Case report

https://www.journal-imab-bg.org

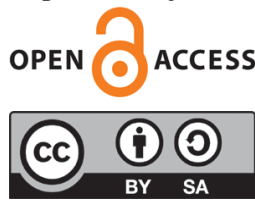

\title{
TRAUMATIC BONE CYST OF THE MANDIBLE: CASE REPORT
}

\author{
Elitsa Deliverska \\ Department of Dental, Oral and Maxillofacial surgery, Faculty of Dental Medi- \\ cine, Medical University - Sofia.
}

\begin{abstract}
Background: Idiopathic bone cavities (IBCs) are osseous pseudocysts with unclear etiology. Their clinical course and response to treatment are poorly understood.

Purpose: The aim of this study is to present a case of a patient with IBC with long-term follow-up.

Patients and Methods: A retrospective case of 16years old male patient with IBC of the jaw is implemented. Medical records of the patient were reviewed for data on presentation and imaging. The patient underwent surgical exploration to confirm the diagnosis. Follow-up radiographs were evaluated for resolution or persistence after the procedure.

Results: The lesion was asymptomatic and discovered as incidental findings. Common radiographic features included scalloping without root resorption or displacement and cortical thinning in lingual aspect expansion. Intraoperative findings showed an empty bone cavity often filled with blood-tinged serous fluid or blood. The histopathology of scrapings from the bony wall showed benign mixed fibrous tissue and no epithelial lining. Radiographic follow-up was 3 years after surgery. After exploration and curettage, the patient had a complete bone fill.

Conclusion: IBC is a rare condition, and several differential diagnosås should be considered. A single procedure to confirm the diagnosis and curettage is sufficient for management.
\end{abstract}

Keywords: bone cyst, pseudocyst, mandible,

\section{INTRODUCTION}

Traumatic bone cysts may be characterized by the presence of an asymptomatic cavity in bone with no epithelial lining. Traumatic bone cysts were described in 1929; they are commonly found in the metaphysis of long bones but are rare in the jaws. [1, 2, 3]

Traumatic bone cysts may be classified as unicameral, simple, solitary, hemorrhagic, or idiopathic.[1, 4, 5, 6, $7,8]$ They are usually asymptomatic and appear on routine radiographies. Because of a lack of unique clinical and radiographic features, it is important to establish the differential diagnosis between traumatic bone cysts and other bone lesions of the jaws, especially translucent lesions. [1]

\section{CASE REPORT}

This is a case report of a 16-year-old patient who presented with a large lesion in the posterior region of the mandible, asymptomatic, and with no previous history of trauma.

A 16 years boy was referred to our department. On a routine, OPG (fig. 1) was detected a solitary radiolucent lesion and CBCT scan was performed. Radiographically, the lesion presented as well demarcated, unilocular radiolucency that scallop adjacent teeth roots, which were vital without evidence of resorption or displacement but with cortical expansion in lingual aspect. (fig. 2, 3) After endodontic treatment of 45 and 46 , the surgery was planned under local anesthesia. The serosanguineous fluid was aspirated, and surgical exploration was performed and revealed an empty bone cavity with smooth walls.

A thin fibrous lining was removed by curettage. It remains unclear whether placing grafts into the defect assists healing, and no bone grafting was used.

Histologically, no signs of the epithelium was found, and the final diagnosis was made as IBC.

The patient was placed on a frequent recall schedule and also began seeing the general practice residency for frequent prophylaxis.

Over the next 3 years, healing was tracked with serial OPG radiographs with no signs of recurrence. (fig. 4, 5)

Fig. 1. Preoperative OPG with initial presentation of the lesion

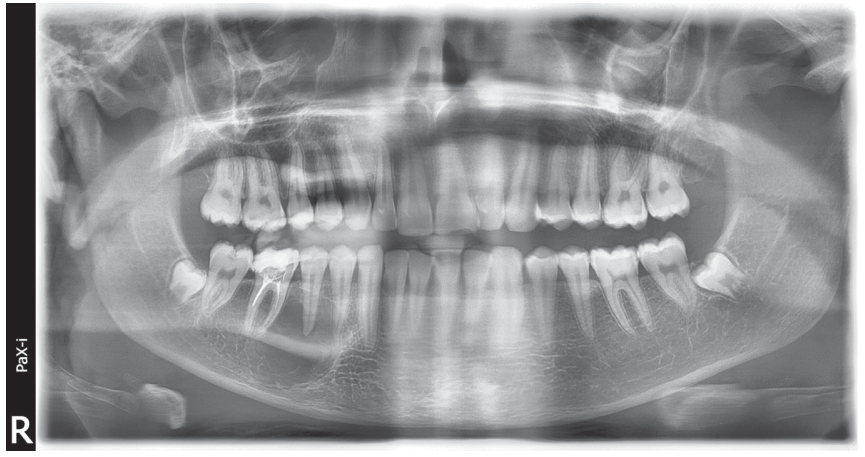


Fig. 2. CT csan of the lesion

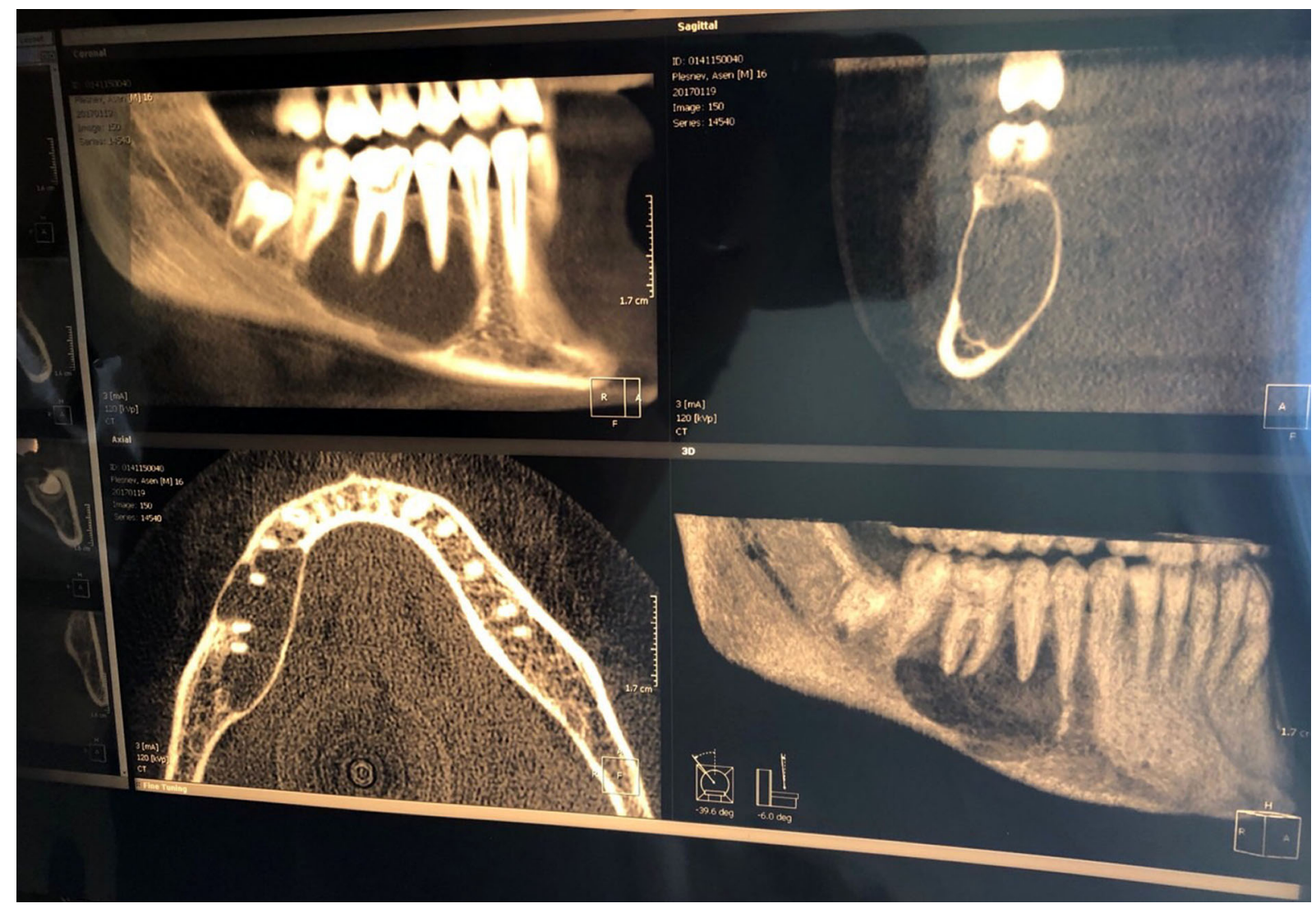

Fig. 3. CT scan of the lesion

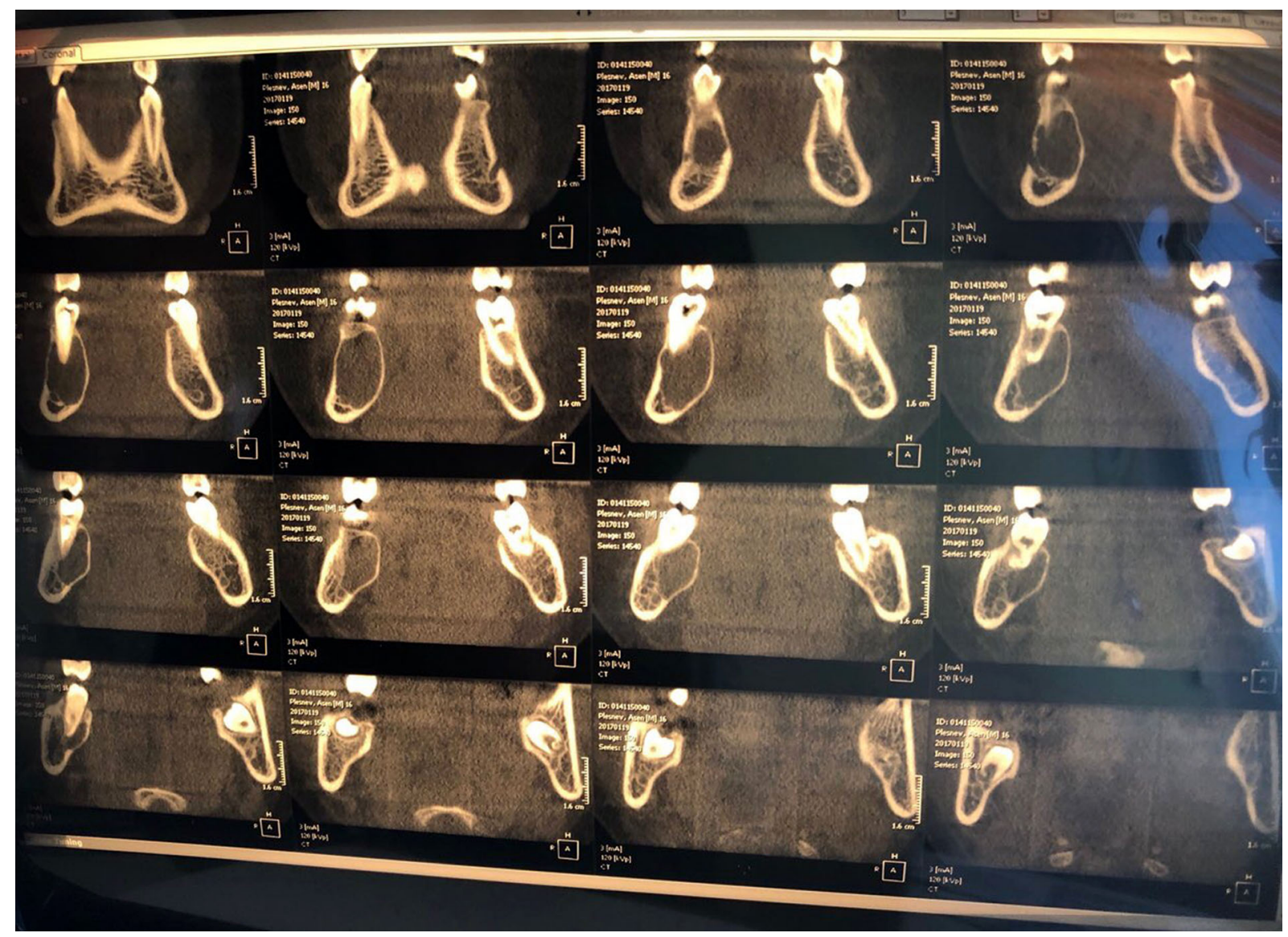


Fig. 4. Postoperative OPG 8 month after surgery

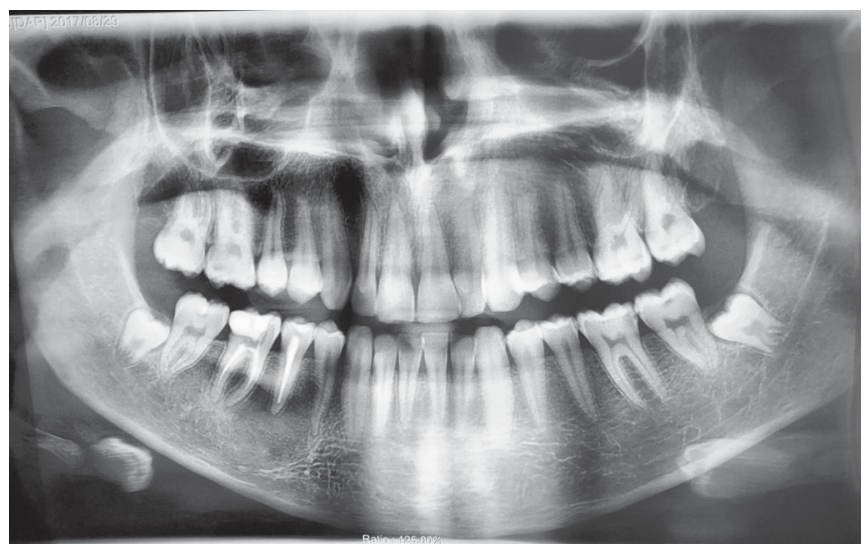

Fig. 5. Postoperative OPG one and a half year after surgery

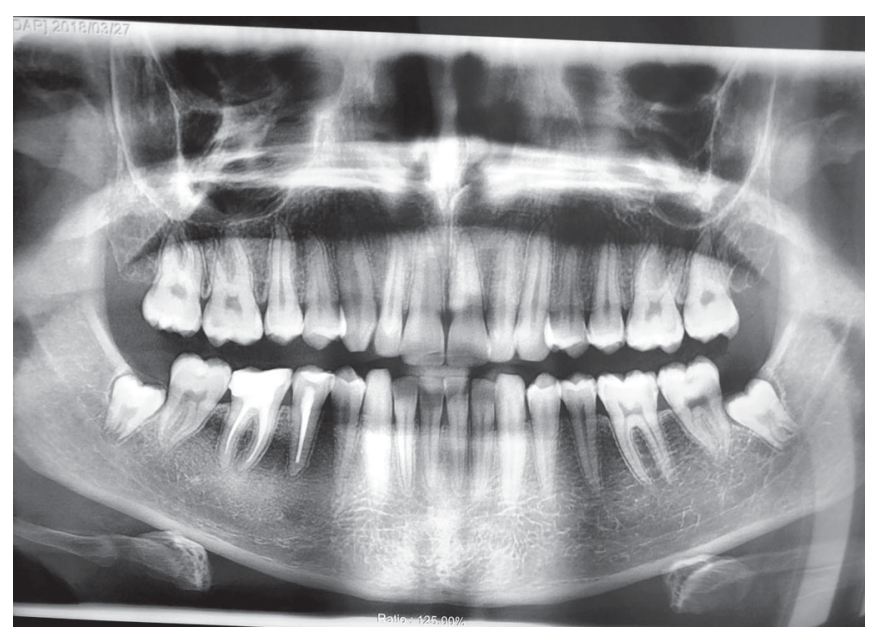

DISCUSSION

Traumatic bone cysts are rare lesions of the jaws. They are classified by the World Health Organization as part of a group of bone lesions that include the ossifying fibroma, fibrous dysplasia of bone, central giant cell lesions, aneurysmatic bone cysts, and cherubism. [1] Although traumatic bone cysts were described at the beginning of the 20th century, the pathogenesis remains unclear and speculative. [9] The most accepted version at present is the traumatic-hemorrhagic theory, which suggests that lesions develop if intramedullary clots due to trauma do not undergo lysis or resolution. [10] This theory explains why traumatic bone cysts occur more often in young individuals (an age at which trauma occurs more often) and also explain the presence of blood within the cavity at the time of surgical exploration. Reports of trauma at the site of lesions and the presence of blood in the cavities, however, are uncom- mon, as seen in our sample. This opens the possibility that microtrauma of teeth and the alveolar ridge are involved in the pathogenesis of traumatic bone cysts [11].

According to several authors, most cases of traumatic bone cysts present in young patients, although they may be detected at any age $[12,13,14]$; our case was similar - the patient was 16 years of old.

Most cases of maxillofacial traumatic bone cysts described in the literature are asymptomatic and do not cause expansion of the cortical area - these cysts are diagnosed as accidental findings in routine radiographs as in our case. $[11,13]$

Traumatic bone cysts generally show up as unilocular radiolucent areas in the posterior portion of the mandible; its margins are scalloped among dental roots $[10,11$, 12] Therefore, traumatic bone cysts should be part of the differential diagnosis of maxillary radiolucent lesions - together with dentigerous cysts, keratocystic odontogenic tumours, ameloblastomas, odontogenic myxomas, aneurismatic bone cysts, focal osteoporotic bone marrow defect, intraosseous vascular malformations, central giant cell lesions, among others. [1]

A few authors have reported the occurrence of multiple traumatic bone cysts, and their association with fibrous/bony lesions - such as the florid cemento-osseous dysplasia - especially in older patients $[15,16,17]$ Providers should be prepared for long-term follow-up in patients treated for multiple IBCs because of the high probability of recurrence.

The histology of traumatic bone cysts reveals only a connective tissue membrane lining the pathologic cavity, characteristic of pseudocysts. Cholesterol crystals, hemorrhagic foci, and osteoclasts may be found $[1,11,18]$. A final diagnosis of a traumatic bone cyst is almost invariably made at the time of surgery; the material available for histology is usually sparse because of the difficulty in removing the thin connective tissue membrane. Surgeons usually encounter an empty cavity, although there may be blood, serum, or both. [1, 19]

The treatment of choice for traumatic bone cysts is surgery for curettage of the bone walls, which generally results in short-term healing $[1,11]$. Recurrences are rare and usually occur within three months of surgery. Cases of multiple cysts or those associated with florid cemento-osseous dysplasia have high recurrence rates - respectively, about $71 \%$ and $75 \%[1,20]$.

\section{CONCLUSION}

The prognosis is usually excellent, although in some cases, IBCs are difficult to treat and require annual followup until radiographic healing has been completely verified. 


\section{REFERENCES:}

1. Martins-Filho PRS, de Santana Santos T, de Araujo VLC, Santos JS, de Souza Andrade ES, da Silva LCF. Traumatic Bone Cyst of the Mandible: A Review of 26 Cases. Braz J Otorhinolaryngol. 2012 Apr;78(2):16-21. [PubMed] [Crossref]

2. Surej Kumar LK, Kurien N, Thaha KA. Traumatic Bone Cyst of Mandible. J Maxillofac Oral Surg. 2015 Jun; 14(2):466-9. [PubMed] [Crossref]

3. Saito Y, Hoshina Y, Nagamine T, Nakajima T, Suzuki M, Hayashi T. Simple bone cyst. A clinical and histopathologic study of fifteen cases. Oral Surg Oral Med Oral Pathol. 1992 Oct;74(4):487-91. [PubMed] [Crossref]

4. Jafee HL, Lichtenstein L. Solitary unicameral bone cyst: With Emphasis on the Roentgen Picture, the Pathologic Appearance and the Pathogenesis. Arch Surg. 1942 Jun;44(6): 1004-25. [Crossref]

5. Kuroi M. Simple bone cyst of the jaw: Review of the literature and report case. J Oral Sur. 1980 Jun; 38(6):456-9. [PubMed]

6. Rushton MA. Solitary bone cysts in the mandible. Br Dent J. 1946 Jul;81(2):37-49. [PubMed]

7. Jones AC, Baughman RA. Multiple Idiopathic Mandibular Bone Cysts in a Patient With Osteogenesis
Imperfecta. Oral Surg Oral Med Oral Pathol. 1993 Mar;75(3):333-7. [PubMed] [Crossref]

9. IARC. Pathology and Genetics of Head and Neck Tumours [OP] (Medicine). Barnes L, Eveson JW, Reichart P, Sidransky D. Editors. WHO. 1st Edition. March 1, 2005. [Internet]

10. Howe GL. 'Haemorrhagic cysts' of the mandible. I. Br J Oral Surg. 1965 Jul;3(1):55-76. [PubMed] [Crossref]

11. Harnet JC, Lombardi T, Klewansky P, Rieger J, Tempe MH, Clavert JM. Solitary Bone Cyst of the Jaws: A Review of the Etiopathogenic Hypotheses. J Oral Maxillofac Surg. 2008 Nov;66(11):2345-8. [PubMed] [Crossref]

12. Forssell K, Forssell H, Happonen RP, Neva M. Simple bone cyst: review of the literature and analysis of 23 cases. Int J Oral Maxillofac Surg. 1988 Feb;17(1):21-4. [PubMed] [Crossref]

13. MacDonald-Jankowski DS. Traumatic bone cysts in the jaws of a Hong Kong Chinese population. Clin Radiol. 1995; 50(11):787-91. [Crossref] 14. Perdigao PF, Silva EC, Sakurai E, Soares de Araujo N, Gomez RS. Idiopathic Bone Cavity: A Clinical, Radiographic, and Histological Study. $\mathrm{Br}$ J Oral Maxillofac Surg. 2003 Dec;
41(6):407-9. [PubMed] [Crossref]

15. Kuhmichel A, Bouloux GF. Multifocal Traumatic Bone Cysts: Case Report and Current Thoughts on Etiology. J Oral Maxillofac Surg. 2010 Jan;68(1):208-12. [ubMed] [Crossref]

16. Razmara F, Ghoncheh Z , Shabankare G. Traumatic bone cyst of mandible: a case series. J Med Case Reports. 2019 Sep 18;13(1):300. [PubMed] [Crossref]

17. Surej Kumar LK, Kurien N, Thaha KA. Traumatic Bone Cyst of Mandible. J. Maxillofac. Oral Surg. 2015 Apr;14(2):466-9. [PubMed] [Crossref]

18. Patil SP, Sodhi SJ, Mishra SS, Farha SS. Solitary Bone Cyst of Posterior Maxilla: A Rare Presentation. Contemp Clin Dent. 2019; 10(1):1669. [PubMed] [Crossref]

19. Satish K, Padmashree S, Rema J. Traumatic bone cyst of idiopathic origin? A report of two cases. Ethiop J Health Sci. 2014 Apr;24(2):183-7. [PubMed] [Crossref]

20. da Costa ED, Roque-Torres GD, Peyneau PD, Godolfim LR, Haiter Neto F, Almeida SM. Simple bone cyst: rare incidental finding in the mandibular condyle by cone beam computed tomography. Gen Dent. 2018 Jan-Feb; 66(1):54-56. [PubMed]

Please cite this article as: Deliverska E. Traumatic Bone Cyst of the Mandible: Case Report. J of IMAB. 2020 AprJun;26(2):3194-3197. DOI: https://doi.org/10.5272/jimab.2020262.3194

Address for correspondence:

Elitsa Georgieva Deliverska

Department of Dental, Oral and Maxillofacial surgery, Faculty of Dental medicine, Medical University- Sofia.

1, Georgi Sofiiski Blvd., Sofia 1431, Bulgaria.

E-mail: elitsadeliverska@yahoo.com, 